\title{
Nursing students' perspective of nurse-patient relationships as a developmental task: A reconstructive-hermeneutic study
}

\author{
Sebastian Partsch*, Claudia Einig \\ Qualification and Curriculum Research, Institute for Public Health and Nursing Research (IPP), University of Bremen, Bremen, \\ Germany
}

Received: May 17, 2021

DOI: $10.5430 /$ jnep.v11n10p54

\author{
Accepted: June 9, 2021 \\ Online Published: June 21, 2021 \\ URL: https://doi.org/10.5430/jnep.v11n10p54
}

\begin{abstract}
Background: Nursing students' first-year experiences can be complex and challenging. The lack of evidence on the subjective educational processes and educational courses of nursing students limits the development of supportive teaching/learning processes. Our study examines the acquisition processes of undergraduate nursing students in Germany, focusing on the subjective perception of learning requirements and the identification of developmental tasks.

Methods: We carried out a qualitative panel study to reconstruct nursing students' developmental process. Data were collected at the end of the first year of nursing students' training through episodic interviews and were analyzed using reconstructivehermeneutical analysis.

Results: This paper, as part of a larger study, highlighted the nurse-patient relationship as one identified developmental task in the first year of training. Students reported experiencing and dealing with various challenges due to uncertainties in finding ways in case understanding, developing their new professional roles, and balancing specific and diffuse role relationships. The students did not have a clear orientation about what characterizes a professional nurse-patient relationship and how it differs from personal relationships. Furthermore, various strategies for coping these challenges were identified, which differ both in perspective and in the ways they deal with the challenges.

Conclusions: The results offer insight into nursing students' subjective educational processes. These insights are expected to aid the development of focused teaching/learning opportunities, thereby assisting students to understand the structure of professional relationships and develop appropriate competencies. For this purpose, it is necessary to develop a systematic concept that focuses and integrates theoretical and practical training.
\end{abstract}

Key Words: Nursing student perspective, Nurse-patient relationship, Developmental task, Reconstructive-hermeneutical analysis, Nursing education

\section{INTRODUCTION AND BACKGROUND}

Nursing students begin experiencing various challenges from the first year of nursing training. ${ }^{[1]}$ To support nursing students in processing an ever-increasing body of knowledge and putting it into practice, the challenge of nursing education is to provide conditions conducive for students to learn in the interplay between their own lifeworld and the theory and practice of nursing. ${ }^{[2,3]}$ However, individual perspectives

*Correspondence: Sebastian Partsch; Email: partsch@uni-bremen.de; Address: Grazer Straße 4, 28359 Bremen, Germany. 
and processes of nursing students' acquisition of training requirements have largely been overlooked. There is a lack of information regarding students' subjective educational processes; thus, developing appropriate curricula and teaching/learning programs is difficult. ${ }^{[4]}$ This could affect the development of students' professional competences as well as their attachment to the profession. ${ }^{[5]}$ Therefore, emphasizing students' perspective can stimulate their interest and be conducive to effective learning. ${ }^{[6]}$

Our project, funded by the German Research Foundation (DFG), draws upon the theory of learner development and educational experience (Bildungsgangstheorie) and the socialization-theoretical approach of developmental tasks. ${ }^{[7]}$ The project aims to analyze nursing students' subjective career and individual needs (subjektiver Bildungsgang); therefore, questions regarding developmental tasks considered important by nursing students and the timing of such considerations are crucial to expand the existing didactic approach and promote the development of competences. In contrast to Havighurst, ${ }^{[8]}$ who developed a rigid normative concept of developmental tasks, the theory of learner development and educational experience posits developmental tasks as social demands on students in specific life situations, which can be individually interpreted as tasks of personal development. ${ }^{[5]}$

The theory of learner development and educational experience approach is used in German academic and vocational education as well as in German general education to analyze students' subjective career and individual needs. However, to the best of our knowledge, no previous study in nursing education has addressed the intersection of the theory of learner development and educational experience and the concept of developmental tasks. While some similarities to research on the theory of learner development and educational experience exist, studies on professional identity or nursing identity focus less on the learning process as subjective perception, interpretation, and processing of practical qualification requirements, and more on observed results.

Therefore, there is a lack of qualitative research focusing on the learner perspective of undergraduate nursing students and their perception of learning requirements relevant to their training. This study aimed to bridge this gap by addressing the following research questions: What are the developmental tasks that nurse students go through during their training? Which interpretations and processing patterns of these developmental tasks can be reconstructed? This paper reflects one part of the whole study and takes a closer look at one of the five identified developmental tasks from beginner nursing students in the first year of German undergraduate nursing programs: building and shaping nurse-patient relationships.
Unlike many other countries, the German nursing education system is not at an academic level and is largely vocational. Consequently, German nursing training is characterized by a high proportion of practical work to provide nursing students a wide range of experience involving patient care early in their training. The program lasts three years and can be completed with a degree in general care, pediatric care, or elderly care. During their three years of training, students are expected to complete 2,100 hours of theoretical and practical training in nursing school and 2,500 hours of practical on-the-job training in different settings, which allows additional time to gain more experience in practical training. Students rotate at regular intervals between nursing school and practice after a theoretical introductory phase. In practical nursing training, clinical supervisors are supposed to regularly provide guidance, but in fact this seldom happens; moreover, such interactions often focus only on the rule-guided execution of nursing actions instead of on soft skills such as nurse-patient relationship building. ${ }^{[9]}$ In this regard, nursing schools largely only teach content from humanistic psychology and the constructivist perspective on communication, and do not take into account the specifics of professional nurse-patient relationships. ${ }^{[10]}$

Nurse-patient relationships are often described as the very core of care and essential to quality of care. ${ }^{[1]}$ According to Oevermann, ${ }^{[12]}$ nurse-patient relationships can primarily be understood as working alliances (Arbeitsbündnisse) in which actions are used to restore bodily and psychosocial integrity to guarantee autonomy of daily practices (Lebenspraxis). Therefore, it is necessary for participants to enter into both a diffused relationship on the patient's side and a specific relationship on the nurse's side. Nurses are primarily required to enter a specific relationship (role-relationship) and also be sensitive and interested in the patient as a whole person (ganze Person). The comprehensive understanding of the patient's situation (case understanding (Fallverstehen)) requires nurses to be receptive to their own emotions and reactions to the patient's behavior. However, they must not allow themselves to be overwhelmed by their own emotions and reactions, but must ultimately distance themselves from them, analyze them, and provide a response that supports the people they are caring for as nurses. ${ }^{[12]}$ Additionally, nursepatient relationships are asymmetrical because the nurse's responsibilities and power are greater than those of the patients. It is, therefore, essential to take this balance of power into account when building relationships. ${ }^{[13]}$ Nurses should strive to address the power imbalance and ensure a relationship, focused on the patient. ${ }^{[14]}$ In this regard, it must also be emphasized that professional communication and interaction, as well as their specifics, are understood as essential 
cornerstones of nurse-patient relationship and, thus, must be considered an essential component of nurse-patient relationships. ${ }^{[15-17]}$

The ability to develop relationships with patients is an important aspect of nursing training. ${ }^{[18]}$ Therefore, fostering nursepatient relationship competences in nurse training is seen as fundamental. ${ }^{[19]}$ Furthermore, nurse-patient relationships provide learning opportunities for nursing students, but students' experiences with nurse-patient relationships are often not considered as learning opportunities. ${ }^{[20,21]}$ Suikkala and Leino-Kipli ${ }^{[22]}$ identified different types of student-patient relationships (mechanistic, authoritative, and facilitative), as well as factors that determine the types and quality of the relationship. Although this study addressed nurse-patient relationships in nursing education, it did not emphasize students' internal perspectives. Albinsson et al. ${ }^{[23]}$ emphasized students' internal perspectives with little focus on the learning process. These researchers concluded that nursing students have little or no prior understanding of nursing and the interactions in nurse-patient relationships, and, therefore, need to learn how to establish an authentic and trusting nurse-patient relationship.

Overall, there is considerable literature, comprising both theoretical and empirical studies, focusing on the nurse-patient relationship. However, these studies focus less on the learning process as the subjective perception, interpretation, and processing of practical qualification requirements. Additionally, the extant studies do not shed light on how nursing students perceive nurse-patient relationships as a developmental task or the strategies they use in dealing with this task. Therefore, the present study, using this perspective, could offer useful insights to develop an understanding of nursing students' perspective.

\section{Methods}

Qualitative and reconstructive research methods are particularly useful for analyzing educational phenomena, which are understood as independent and socially determined processing of developmental tasks. ${ }^{[24]}$ To reconstruct these development processes, we conducted a qualitative panel study with guideline-based interviews. We used the integrative approach of Kruse ${ }^{[25]}$ by implementing a reconstructive-hermeneutic analysis as our methodological framework. Kruse analyzed the seemingly different approaches of qualitative social research (e.g., the grounded theory methodology and documentary method) with regard to methodological-methodological commonalities and transformed them into his own approach. The method assumes that qualitative research is based on an interpretative reconstruction of linguistic-communicative phenomena. ${ }^{[25]}$

\subsection{Recruitment and sample}

A total of 26 nursing students were recruited from all nursing training specialties (general care, pediatric care, and elderly care) and from nine nursing schools in different cities of Germany. The selected schools were contacted, informed about the project, and were requested to allow students to participate. The project was presented by research assistants in different classes, whereupon the students could volunteer to participate. Additionally, teachers acted as gatekeepers for the selection of suitable participants with varying abilities. To ensure variations in influencing factors, we designed a qualitative sample plan (see Table 1) and varied the characteristics that could influence the perception and processing of developmental tasks, such as gender, age, qualifications, previous nursing experience (e.g., civilian service, internship, volunteering), and previous nursing training (e.g., nursing assistant).

This is a qualitative sampling in which participants were selected by contrastive case selection. In contrast to representative sampling, the heterogeneity of the field is represented by a maximum structural variation of the sample. ${ }^{[25]}$ As the analysis of the interviews progressed, it became apparent that the data were becoming increasingly saturated, meaning that no additional nursing students needed to be recruited.

Table 1. Sample plan

\begin{tabular}{|c|c|c|c|c|c|c|c|c|c|c|c|c|c|c|c|}
\hline \multirow[t]{2}{*}{ Training/Section } & & \multicolumn{3}{|c|}{ Gender } & \multicolumn{2}{|l|}{ Age } & \multicolumn{2}{|c|}{$\begin{array}{l}\text { General } \\
\text { School Years }\end{array}$} & \multicolumn{3}{|c|}{$\begin{array}{l}\text { Starting Date of } \\
\text { Nursing } \\
\text { Training }\end{array}$} & \multicolumn{2}{|c|}{$\begin{array}{l}\text { Prior } \\
\text { Nursing } \\
\text { Experience }\end{array}$} & \multicolumn{2}{|c|}{$\begin{array}{l}\text { Prior } \\
\text { Nursing } \\
\text { Training }\end{array}$} \\
\hline & & $\mathbf{f}$ & $\mathbf{m}$ & d & $18-25$ & $25+$ & $9-10$ & $10+$ & 1.4 & 1.8 & 1.10 & Yes & No & Yes & No \\
\hline General Care & 12 & 9 & 2 & 1 & 8 & 4 & 4 & 8 & 8 & 4 & - & 8 & 4 & 1 & 11 \\
\hline Pediatric Care & 5 & 5 & - & - & 4 & 1 & 4 & 1 & 5 & - & - & 1 & 4 & - & 5 \\
\hline Elderly Care & 6 & 4 & 2 & - & 1 & 5 & 4 & 2 & 3 & 1 & 2 & 4 & 2 & 2 & 4 \\
\hline General Care (new) & 3 & 3 & - & - & 3 & - & 1 & 2 & - & - & 3 & 3 & - & 1 & 2 \\
\hline Total & 26 & 21 & 4 & 1 & 16 & 10 & 13 & 13 & 16 & 5 & 5 & 16 & 10 & 4 & 22 \\
\hline
\end{tabular}




\subsection{Data collection}

Developmental tasks are subjective interpretations of social requirements. Qualitative interviews are a way to determine subjective patterns of interpretation and action. Therefore, we conducted episodic interviews using a semi-structured interview guide to combine story-generating questions with a thematic focus based on a guideline to capture episodic and semantic knowledge. ${ }^{[26]}$ The interviews were conducted between April and August 2019. Most interviews were conducted in the participants' respective nursing schools and lasted between 60 and 120 min. Participants' permission was obtained for audio recording, and a Tascam DR-05X recorder was used. In addition, after each interview, various aspects of the interview were recorded in a field protocol. The recordings were transcribed verbatim and subsequently anonymized by an authorized transcription office.

\subsection{Data analysis}

Reconstructive-hermeneutic analysis by Kruse ${ }^{[25]}$ combines three concepts: micro-language detailed analysis on a pragmatic, syntactic, and semantic level; use of objective analyzing heuristics; and use of methodical analyzing heuristics. First, an open phase of micro-language analysis was conducted, which is similar to open coding in grounded theory. ${ }^{[27]}$ The various analytical heuristics were discussed and tested to avoid the use of deductive and determinative heuristics. The aim of our analysis was to identify the mentioned topics, theories, and lexical fields (the what) and the ways in which they are presented (the how). Subsequently, these two elements (the what and the how) were related to each other and different types of interpretations were generated. Finally, the superordinate or underlying sense was reconstructed by cross-case systematic case comparisons. Finally, we took an increasingly abstract perspective and focused on the research questions. For the analysis, we used MAXQDA software.

\subsection{Rigor and ethical considerations}

Transparency was pursued through precise documentation of previous understanding and preconceptions, data collection methods and context, methods of data analysis, and analyzing groups. The two research assistants met at least once a week, at least once a month with the analyzing group at the Institute for Public Health and Nursing Research University of Bremen, and at least every three weeks with the head of the project for debriefing in order to develop alternative readings and the collegial validation of founded interpretations.

Considering the European General Data Protection Regulation, ethical approval was obtained from the University of Bremen's Ethics Committee in May 2019. Informed written consent was obtained, and participants were assured of their rights of autonomy, confidentiality, and self-determination.

\section{RESULTS}

Our analysis identified building and shaping nurse-patient relationship as a developmental task in the first year of training. This developmental task is multifaceted and perceived differently. We discovered three categories that comprised this developmental task and different strategies to deal with them.

\subsection{Developmental task description-Building and shap- ing nurse-patient relationships \\ 3.1.1 Developing own understanding of nursing role}

Students in the study reported widespread uncertainties regarding what the role of a professional nurse in the nursepatient relationship actually entails. As a result, distorted expectations and uncertainties about one's own role develop. We noted that occasionally students could not meet their own expectations to fulfill their role in the relationship building process. In reflecting on a memorable situation regarding relationship building with patients, one student commented, "I have not really figured out how to react perfectly every time, that is always situational" (P19) (The quotations were translated from German by the authors and verified by external translators.). The reasons for this uncertainty are a lack of specialist knowledge, their status in the institution, and distorted ideas regarding seemingly correct/incorrect actions within their role. In addition, students had different attitudes regarding responsibility in nursing relationships, especially when it came to assuming a professional role. One student shared that successful relationship building is only possible through mutual interaction in accordance with the respective expectations, thus also assigning a corresponding responsibility to the patient. At a further level of relationship building, the students also perceived the challenge to prioritize the fulfillment of multiple patients' needs when different nursing tasks get accumulated. In this context, one student commented that when caring for multiple patients, it is challenging "[...] to meet the needs of patients and somehow to be able to, yes, to be able to perceive their needs and not to decide over their heads" (P14).

Regarding communication, students appeared to have a normative idea of professional communication but did not know what professional communication could or should be. Most students were unable to identify any further learning needs, but perceived various communicative situations as challenging as illustrated in the following excerpt. When asked what else he would like to learn in terms of communication, one student responded: "Not really, I think I know most of it already. [...] So, that is, I am an instinctive person, as far 
as that is concerned. [...] And actually always hit the right direction" (P26).

\subsubsection{Developing case understanding}

The students saw themselves primarily as representatives of the patients and their needs, supporting them through crisis coping. When asked what is important in caring for patients, one student stated, "For me personally, it is always very important that the patients know that they do not have to go through this alone" (P24). To be able to understand a patient's situation, students emphasized case understanding as one of their main objectives. Another student stated, "This background, what else did they experience, in order to perhaps find connections, why it happened like that or why he reacts like that now?" (P23). Evidently, the students did not know exactly what can or should be the focus of case understanding.

Students' experiences revealed that they preferred for the patients to be as open as possible about their sensitivities and issues, to allow students to develop a comprehensive understanding of the case. In reflecting on what is most important to her in her relationship with patients, one student stated, "Openness and honesty [are important]. Therefore, the patients must be able to open up to me, so that we can have a good conversation and build a good relationship; and it must be honest" (P22). However, it also became clear that students could only deal with difficulties in specific situations. Students felt challenged when patients behaved in an unexpected manner (e.g., rejecting treatment) and when they had to interact with patients experiencing negative emotions While narrating a memorable and demanding situation, one participant shared, "A patient who was very open told me that her grandson $[\ldots]$ had committed suicide $[\ldots]$ and that was just very shocking because I was not expecting that [during nursing anamnesis]" (P4). These situations may lead to conflicts or feelings of helplessness. In such situations, a lack of self-reflection can lead to inadequate, unprofessional, or unfair behavior. Another participant shared a particularly challenging situation: "The [patient's] mother just drove me crazy [...] And then I thought to myself: 'Oh.' Of course, I had to stay calm. But at one point I became so upset that I thought: 'Nah [sic]. [I do] Not [want to deal with this] anymore. Not really' [...]" (P21).

\subsubsection{Balancing specific and diffuse relationships}

In recounting and reflecting on challenging situations that the students remember vividly, it is clear that some students became more involved in nurse-patient relationships ("I try to be close with patients. We have been instructed to remain detached, so I think I am a bit too close with patients [however] I do not think that is a bad thing [...]" [P12]) while others remained more detached ("[I do this] because we are automatically very close with patients because of the work we do, so I find it all the more important to keep a healthy distance" [P4]).

Students experienced uncertainty when they became deeply involved with patients in the nurse-patient relationship. In the narrative of a student's challenging situation in which parents lost their child, one student shared, "I do not think it is appropriate to show compassion, but, in what way? Well, I always have to think about, 'No, maybe you're not allowed to do that.' So that I'm still thinking, 'I'm here at work, I'm not here in private at the moment somewhere'" (P4). This uncertainty was usually owing to a lack of self-reflection. Some students were unable to manage their own emotions during the process of developing a comprehensive understanding. In recounting a situation with a very demanding patient, one student reported, "I felt helpless and frustrated; that is why I broke up the situation, I tried to remain composed, to remain professional, and to analyze why the patient was suffering" (P15). This was especially important when students recognized situations in which certain processes were not functioning properly. Further, simultaneously taking a specific role and being consciously involved as a whole person was seen to be challenging in itself. Another student shared, "[The patient] called everyone 'mom' because he missed his mom. And that was a situation where I could not tell the difference between closeness and distance" (P18).

\subsection{Strategies to deal with the developmental task}

In processing the developmental task, students' strategies varied in terms of the perspective and the ways of dealing with the challenges. One of the most common reactions in challenging relationships was to search for explanations for patients' behaviors. These explanations were primarily sought in the clinical picture and in the patient's culture or social background. When asked what challenged him in caring for a patient, a student stated, "I must deny. Da/ (...) Yes, what does exhaust mean? Uh, (.) sure, you just (.) do not always get the answer you want. But (.) this is due to the clinical picture" (P25). In addition, the students used their perceived behavior as an occasion for self-reflection or as learning impulses. They questioned their actions and, if necessary, adapted for forthcoming situations. Another student reflected in reference to a patient he particularly remembered, "it simply gave me another perspective, that even in old age one can feel depressed, which [...] then perhaps is somehow justified, but that I can understand it" (P3).

When students adopted a passive role, they passed responsibility of the nurse-patient relationship onto their colleagues, which signaled a rejection of their own ideas and abilities to 
avoid potential conflicts. In a narrated situation, the patient rejects certain actions, resulting in conflict between patient and student. The student described the following: "and then I said: 'Sorry, but I am not going to [treat that patient] again.' And that works too. Then you can [treat someone else]" (P20).

When students adopted an active role, they reflected on the situation, consciously adapted to it, or asked other nurses for advice. In addition, consciously distancing themselves from the patient can help nursing students cope with difficult cases. Starting from the narrative of an escalated situation, one student reported, "Once I spoke with [the patient], I apologized and said that I hoped that [...] we would somehow [...] reach a compromise for the next weeks of his stay; we agreed that his stay would be beneficial for him. Afterwards, he agreed to follow treatment this way" (P14).

Some students were particularly keen to compensate for their lack of competence; they sought to accomplish this by observing other nurses. However, students often rated this strategy as ineffective because of inadequate feedback. When asked what support the students need and what is lacking in their training, one student stated, "No one ever tells me that and also if I ask them, they always just say, 'Yes, I think you have a good patient contact"' (P14). Students were often unable to solve problems simply by observing their clinical supervisors or colleagues. Therefore, students reported professional experience to be essential. When asked what might support him in his development, a student reported the following: "I do not have that much experience yet. Um, so what exactly I should do, I do not know. I think I have to decide intuitively or situationally" (P4).

\section{DISCUSSION}

Our findings showed that students perceive it as a challenge to find and define their role in professional nurse-patient relationships. Despite theoretical training, they neither have a clear idea of what the specifics of professional nursing relationships are, nor an awareness of the power structure or responsibility in relationships. ${ }^{[12,13]}$ Similar to Albinsson et al.'s study, ${ }^{[23]}$ the present findings reveal that nursing students have limited prior understanding but express a desire to find out how to form nurse-patient relationships. In this context, it could be said that students prefer specific feedback regarding their development of nurse-patient relationships, recognizing that such feedback offers an opportunity to learn. However, although nursing students' experiences with nurse-patient relationships offer potential learning opportunities, they are often not viewed or utilized as such. ${ }^{[20,21]}$ Nurses and nursing students lacking sufficient professional relationship competencies rely on the methods learned in their private life ways

Published by Sciedu Press to shape relationships, ${ }^{[28]}$ which could explain why students did not recognize the need to develop specific competencies (e.g., professional communication). Therefore, drawing from their own private experiences could have led to experiencing various challenging situations.

Similar to previous studies, our data confirmed that one of the main objectives of the students was to support their patients. ${ }^{[29]}$ It is also important for students to focus on acquiring a comprehensive view of their patients' situations, so they are able to understand the condition afflicting them. In doing so, the students did not seem to know exactly what the focus of understanding should be. It is essential for nurses to remain engaged in nurse-patient relationships and to strive for equality within such relationships. ${ }^{[14,30]}$ However, previous research suggests that although students have an particular interest in openly communicating and forming relationships with patients during their first year of training, this interest diminishes over the course of their training. ${ }^{[20]}$

Our data showed that dealing with unexpected behavior and negatively perceived emotions is a significant burden for students and may foster feelings of helplessness. Task-related emotional influence is essential to nursing work, which is why it has been referred to as sentimental work. ${ }^{[31]}$ In this context, patients wish to enter into a largely open relationship (e.g., outspoken, thematization of all contents). ${ }^{[12]}$ Various studies have confirmed that it is difficult for nursing students to manage their emotions. ${ }^{[32]}$ In addition, previous negative experiences, such as unexpected verbal or physical attacks, can make students feel insecure. ${ }^{[33]}$ The ability to perceive and regulate one's own emotions is an important prerequisite for empathy. ${ }^{[34]}$ It is a complex process involving the trained regulation, shaping, or suppression of feelings to maintain a professional outward demeanor and to support patients' emotional management. ${ }^{[35]}$ However, students often lack the self-reflection skills required to manage their emotions to achieve the objectives demanded by the profession. Without adequate support, demands of emotional labor can lead to stress and can negatively impact work performance. ${ }^{[36]}$

During emotional labor, students often experience feelings that they are unable reflect and channel in a constructive manner. Patients' life history can influence the nurse-patient relationship without them being aware of it, and the same can happen through the students. These elements can distort both participants' perception of the situation, which might negatively influence the care process. These phenomena are known as transference and countertransference. ${ }^{[37]}$ According to Oevermann's theory, ${ }^{[12]}$ nurses need to be perceptive of their own emotions and their reactions to patients' behavior, to develop a comprehensive understanding of the patients' 
situations. However, there is limited nursing research and nursing concepts on transference and countertransference phenomena. ${ }^{[38]}$

In this context, our data showed that students had different attitudes, uncertainties, and inner conflicts toward getting personally involved in nurse-patient relationships. Moreover, according to Raeve, ${ }^{[39]}$ to achieve high quality care, the connection between nurse and patient should be intimate but not too close. Likewise, Hechinger et al. ${ }^{[40]}$ state that some nurses tend to become more professionally involved, while others prefer to focus more on themselves, bringing more personal qualities to the relationship. The present data showed that the students had various uncertainties regarding being involved as a whole person, the role action required for the professional relationship, and how they should balance this interaction situationally. To frame this discussion solely in terms of closeness and distance would be inadequate, as this matter is not only about a rigid attitude but also about consciously involving the whole person situationally without inflicting excessive emotional burden on the nurse.

\section{Limitations}

This study was conducted with German undergraduate nursing students; therefore, the findings are difficult to generalize to other countries because of the special educational circumstances. Nevertheless, our findings provide significant insight into the learning experiences of student nurses in Germany, partly confirming the findings of other international studies. Therefore, our findings could have implications for other countries with similar educational practices.

Additionally, using theoretical framing involves the risk of adapting the results to the theory, thereby distorting or overlooking certain aspects of the data. However, when theoretical framing is performed at the end of the analysis, it can help sharpen and concretize the results. The analysis method aims to achieve the greatest possible openness through the various fine analysis steps to reflect different assumptions and to approach the data with openness. Nevertheless, this requires a high degree of self-reflexivity on the part of the researchers.

\section{Conclusion}

The aim of this study is to identify nursing students' developmental tasks and the strategies they use to deal with the said tasks, to indicate formal educational opportunities and create an empirical basis for the development of curricula. The developmental task of building and shaping nurse-patient relationship already provides relevant hints regarding how students perceive and deal with learning requirements in their first year of training. Nursing action requires the establish- ment of a nurse-patient relationship; however, this may be different from the relationships students would have likely encountered thus far in their socialization. The students experience various challenges due to uncertainties about what characterizes a professional nurse-patient relationship and how it differs from personal relationships. They are often unclear about how to deal with the different types of relationships, and how to balance the interaction of role action while being involved as a whole person in the professional relationship. In this respect, nursing students appear to lack sufficient theoretical and practical support in the current educational context.

As nursing students in Germany gain practical experience at a very early age, the development and shaping of nurse-patient relationships should be supported from the beginning of training as a core task of professional nursing. It is important to recognize these experiences and challenges as possible learning occasions and to address them with the help of targeted didactic methods to support the students in their learning process and to minimize uncertainties. Therefore, it is important that theoretical training early on caters to the specifics of the nurse-patient relationship, such as specifics of case understanding or balancing specific and diffuse role relationships. Students must increasingly be able to develop an idea of how a professional nurse-patient relationship differs from a personal relationship and how they could balance and manage the different demands of a professional relationship.

The results provide teachers with various suggestions for preparing students for probable challenges before their first practical experiences as well as teaching them possible professional strategies for dealing with them. In addition, experiencing challenging situations in nurse-patient relationships can be used specifically for reflections or learning opportunities including role playing, and so on. However, it is necessary that teachers possess a certain awareness and sensitivity toward this topic, which may be developed through these results. In practice, it would be useful for clinical supervisors to jointly analyze situations, provide differentiated feedback, and explain their professional actions to students. This is especially important in complex aspects, such as the conscious involvement in a nurse-patient relationship or in instances of transference and countertransference.

However, a more differentiated didactic analysis based on the results and an extended understanding is necessary for the development of a systemic model combining theoretical and practical education. Over the course of the overall study, different development paths in the processing of developmental tasks will be identified. From the results, further conclusions could be drawn regarding the subjective significance of teach- 
ing programs in relation to developmental tasks in different phases of nursing education.

\section{ACKNOWLEDGEMENTS}

The authors thank Ingrid Darmann-Finck, the analyzing group at the Institute for Public Health and Nursing Re- search University of Bremen and the nursing students who participated in the study.

\section{CONFLicts OF INTEREST Disclosure}

The authors declare that there is no conflict of interest.

\section{REFERENCES}

[1] Porteous DJ, Machin A. The lived experience of first year undergraduate student nurses: A hermeneutic phenomenological study. Nurse Educ Today. 2018 Jan; 60: 56-61. PMid:29045912 https: //doi.org/10.1016/j.nedt.2017.09.017

[2] Darling-Hammond L, Flook L, Cook-Harvey C, et al. Implications for educational practice of the science of learning and development. Appl Dev Sci. 2020 Apr 2; 24(2): 97-140. https: //doi.org/10.1080/10888691.2018.1537791

[3] Ekebergh M. A learning model for nursing students during clinical studies. Nurse Educ Pract. 2011 Nov; 11(6): 384-9. PMid:21489878 https://doi.org/10.1016/j.nepr.2011.03.018

[4] Kunze I, Trautmann M, Meyer MA. Zum Stand der Bildungsgangforschung und Bildungsgangdidaktik [On the state of the theory and didactics of learner development and educational experience [Internet]. Präsentation presented at: Kongress der Deutschen Gesellschaft für Erziehungswissenschaft; 2010 [cited 2021 Apr 23]. Mainz. Available from: http://www.rhinodidactics.de/Arti kel/bildungsgangdidaktik-2010-12-01.html

[5] Hericks U. Professionalisierung als Entwicklungsaufgabe: Rekonstruktionen zur Berufseingangsphase von Lehrerinnen und Lehrern [Professionalization as a developmental task: reconstruction of teachers career entry phase]. 1. Aufl. Wiesbaden: VS, Verl. für Sozialwiss; 2006. 496 p. (Studien zur Bildungsgangforschung).

[6] Schunk DH, Zimmerman BJ. Motivation and self-regulated learning: theory, research, and applications. [Internet]. Hoboken: Taylor and Francis; 2012 [cited 2020 Aug 29]. Available from: http://public.ebookcentral.proquest.com/choic e/publicfullrecord . aspx?p=995650

[7] Quenzel G. Das Konzept der Entwicklungsaufgaben [The concept of developmental tasks]. In: Hurrelmann K, editor. Handbuch Sozialisationsforschung. 8., vollständig überarbeitete Auflage. Weinheim: Beltz; 2015. p. 233-50. (Pädagogik).

[8] Havighurst RJ. Developmental tasks and education. 3rd print. New York: McKay; 1974. 119 p.

[9] Fichtmüller F, Walter A. Pflege gestalten lernen - pflegedidaktische Grundlagenforschung [Learning to shape nursing - nursing didactic basic research]. In: Ertl-Schmuck R, Fichtmüller F, editors. Theorien und Modelle der Pflegedidaktik: eine Einführung. Weinheim: Juventa-Verl; 2010. p. 91-121.

[10] Georg Thieme Verlag KG. I care LernPaket Pflege; Anatomie Physiologie; Krankheitslehre. 2020.

[11] Peplau HE. Interpersonal relations in nursing: A conceptual frame of reference for psychodynamic nursing. New York: Springer; 2004.

[12] Oevermann U. Professionalisierungsbedürftigkeit und Professionalisiertheit pädagogischen Handelns [Need for professionalization and professionalization of pedagogical action]. In: Kraul M, Marotzki W, Schweppe C, editors. Biographie und Profession. Bad Heilbrunn/Obb: Verlag Julius Klinkhardt; 2002. p. 19-63.
[13] Darmann I. Anforderungen der Pflegeberufswirklichkeit an die kommunikative Kompetenz von Pflegekräften [Demands on the interpersonal skills of nurses in their daily practice]. Pflege. $2000 \mathrm{Aug}$; 13(4): 219-25. PMid:11022570 https://doi .org/10.1024/1012-530 2.13.4.219

[14] National Council of State Boards of Nursing, Inc., editor. A nurse's guide to professional boundaries [Internet]. 2018 [cited $2021 \mathrm{Apr} 19]$. Available from: https://www.ncsbn.org/ProfessionalBoun daries_Complete.pdf

[15] Blumer H. Symbolic interactionism: perspective and method. Nachdr. Berkeley, Calif.: Univ. of California Press; 2009. 208 p.

[16] Kourkouta L, Papathanasiou I. Communication in Nursing Practice. Mater Sociomed. 2014; 26(1): 65. PMid:24757408 https : //doi.org/10.5455/msm. 2014.26.65-67

[17] Sheldon LK, Foust JB, Sheldon LK, et al. Communication for nurses: talking with patients. Third edition. Burlington, MA: Jones \& Bartlett Learning; 2014. 291 p.

[18] Lewallen LP, DeBrew JK. Successful and unsuccessful clinical nursing students. J Nurs Educ. 2012 Jul 1; 51(7): 389-95. PMid:22533497 https://doi.org/10.3928/01484834-20120427-01

[19] Ashton KS. Teaching nursing students about terminating professional relationships, boundaries, and social media. Nurse Educ Today. 2016 Feb; 37: 170-2. PMid:26602238 https://doi.org/10.1016/j.nedt.2015.11.007

[20] Solvoll BA, Heggen KM. Teaching and learning care - Exploring nursing students' clinical practice. Nurse Educ Today. 2010 Jan; 30(1): 73-7. PMid:19581026 https://doi.org/10.1016/j.ne dt. 2009.06.003

[21] Suikkala A, Leino-Kilpi H, Katajisto J. Factors related to the nursing student-patient relationship: The students' perspective. Nurse Educ Today. 2008 Jul; 28(5): 539-49. PMid:17935835 https : //doi.org/10.1016/j.nedt.2007.09.004

[22] Suikkala A, Leino-Kilpi H. Nursing student-patient relationship: Experiences of students and patients. Nurse Educ Today. $2005 \mathrm{Jul} ; 25(5)$ : 344-54. PMid:15916836 https : //doi.org/10.1016/j.nedt. 2 005.03 .001

[23] Albinsson G, Carlsson-Blomster M, Lindqvist G. In search of a caring relationship - Nursing students' notions of interactions in the nurse-patient relationship. Nurse Educ Pract. 2021 Jan; 50: 102954. PMid:33360788 https://doi.org/10.1016/j.nepr.2020.10 2954

[24] Koller HC. Bildung und Biographie. Zur Bedeutung der bildungstheoretisch fundierten Biographieforschung für die Bildungsgangforschung [Education and biography. On the importance of biographical research based on education theory for research on educational pathways]. In: Schenk B, editor. Bausteine einer Bildungsgangtheorie. Wiesbaden: VS Verlag für Sozialwissenschaften; 2005. p. 47-66. https://doi .org/10.1007/978-3-322-80754-0_3

[25] Kruse J. Qualitative Interviewforschung: ein integrativer Ansatz [Qualitative interview research: An integrative approach]. 2., überar- 
beitete und ergänzte Auflage. Weinheim Basel: Beltz Juventa; 2015. 707 p. (Grundlagentexte Methoden).

[26] Flick U. Das Episodische Interview [The episodic interview]. In: Oelerich G, Otto H-U, editors. Empirische Forschung und Soziale Arbeit: Ein Studienbuch. Wiesbaden: VS Verlag für Sozialwissenschaften; 2011. p. 273-80. https ://doi .org/10 .1007/978-3 -531-92708-4_17

[27] Strauss AL. Grundlagen qualitativer Sozialforschung: Datenanalyse und Theoriebildung in der empirischen soziologischen Forschung [Basics of qualitative research: Grounded theory procedures and techniques]. Unveränd. Nachdr. d. 2. Aufl. 1998. München: Fink; 2007. 372 p. (UTB für Wissenschaft Uni-Taschenbücher).

[28] Pohlmann M. The nurse-patient relationship results of an examination about relationships between patients and nurses in hospitals. Pflege. 2006; 19(3): 156-62. PMid:16821324 https://doi.org/ $10.1024 / 1012-5302.19 \cdot 3.156$

[29] Halldorsdottir S. The dynamics of the nurse-patient relationship: introduction of a synthesized theory from the patient's perspective. Scand J Caring Sci. 2008 Dec; 22(4): 643-52. PMid:18803604 https://doi.org/10.1111/j.1471-6712.2007.00568.x

[30] Snellman I, Gedda KM. The value ground of nursing. Nurs Ethics. 2012 Nov; 19(6): 714-26. PMid:22547487 https ://doi .org/10 $.1177 / 0969733011420195$

[31] Strauss A, Fagerhaugh S, Suczek B, et al. Sentimental work in the technologized hospital. Sociol Health Illn. 1982 Nov; 4(3): 254-78. PMid:10260459 https://doi.org/10.1111/1467-9566.ep10 487954

[32] Bhurtun HD, Azimirad M, Saaranen T, et al. Stress and coping among nursing students during clinical training: An integrative review. J Nurs Educ. 2019 May 1; 58(5): 266-72. PMid:31039260 https://doi.org/10.3928/01484834-20190422-04
[33] Angel S, Vatne S. Vulnerability in patients and nurses and the mutual vulnerability in the patient-nurse relationship. J Clin Nurs. 2016 May; 26(9-10): 1428-37. PMid:27626897 https://doi .org/10.1111/ jocn. 13583

[34] Herpertz S, Schütz A. "EMO-TRAIN": Ein Interventionsprogramm zur Förderung von Empathie, Emotionswahrnehmung und -regulation ["EMO-TRAIN": An intervention program to promote empathy, emotional perception and regulation]. In: Roth $\mathrm{M}$, Schönefeld V, Altmann T, editors. Trainings- und Interventionsprogramme zur Förderung von Empathie [Internet]. Berlin, Heidelberg: Springer Berlin Heidelberg; 2016. p. 141-55. http://link. springer.com/10.100 7/978-3-662-48199-8_11 PMid:27267500 https ://doi.org/ 10.1007/978-3-662-48199-8_11

[35] Grandey AA, Sayre GM. Emotional labor: Regulating emotions for a wage. Curr Dir Psychol Sci. 2019 Apr; 28(2): 131-7. https://doi.org/10.1177/0963721418812771

[36] Delgado C, Upton D, Ranse K, et al. Nurses' resilience and the emotional labour of nursing work: An integrative review of empirical literature. Int J Nurs Stud. 2017 May; 70: 71-88. PMid:28235694 https://doi.org/10.1016/j.ijnurstu.2017.02.008

[37] Salzberger-Wittenberg I. Psycho-analytic insight and relationships: a Kleinian approach. 2008.

[38] Bapat AC, Bojarski EF. Transference and countertransference in palliative care \#371. J Palliat Med. 2019 Apr; 22(4): 452-3. PMid:30933569 https://doi .org/10.1089/jpm. 2019.0042

[39] Raeve $\mathrm{L}$ de. Trust and trustworthiness in nurse-patient relationships. Nursing Philosophy. 2002 Jul; 3(2): 152-62. https ://doi .org/10 $.1046 / \mathrm{j} .1466-769 \mathrm{x} .2002 .00090 . \mathrm{x}$

[40] Hechinger M, Mayer H, Fringer A. Kenneth Gergen's concept of multi-being: an application to the nurse-patient relationship. Med Health Care and Philos. 2019 Dec; 22(4): 599-611. PMid:30989571 https://doi.org/10.1007/s11019-019-09897-4 